\title{
Introduction of New DNA Marker Sets in Australian Forensic Laboratories
}

\section{Linzi Wilson Wilde*}

Forensic Scientist, ANZPAA National Institute of Forensic Science, Melbourne, VIC, Australia

Technological advances in DNA profiling have been rapid and significant over the past few years. The impact of these advances, not only on the justice system but in all areas of biological science, has brought DNA analysis into the public eye and dramatically increased the range of legal cases where DNA evidence has been useful.

The Profiler Plus ${ }^{\mathrm{TM}}$ DNA marker system has been in use by Australian jurisdictions for approximately twelve years, allowing over 500,000 DNA 'Profiler Plus' profiles to be added to the National Criminal Investigation DNA Database (NCIDD).

Police Commissioners requested that ANZPAA National Institute of Forensic Science initiate a project to replace the Profiler Plus system with the latest technology. The resulting Advancing DNA Analysis Project introduces a new DNA marker system that will continues to ensure that forensic science in Australia provides consistent quality results, meeting international best practice.

The new DNA marker system operates much as the old system but with improved technology, that is designed to minimise the effects of any inhibitors that may be present in the sample, which significantly increases the chances of obtaining a DNA profile.

The old system is still valid and produces powerful, reliable and robust results - the new system simply provides more information and performs better in degraded or compromised samples. If a full profile was obtained there will generally be no benefit in revaluating or reassessing previous convictions based on the DNA match as it will not normally provide new evidentiary information.

The new system offers more DNA markers which provide an improved ability to distinguish between related individuals. Where the new DNA system is of particular use, is where results cannot currently be obtained with certain types of samples, where there are partial low level results (such as degraded samples from criminal casework, remains from unidentified deceased or missing persons and mass fatality incidents).

While the new DNA marker system is being phased in, there will be a number of cases before court that use one system of analysis and other cases which use the other. This is offset with the huge gain in additional information and potential time efficiencies of using the new system.

There are numerous benefits to the community in using the new DNA analysis system, particularly in potentially solving more crime, identifying recidivism, identifying missing persons and for use in disaster victim identification involving difficult samples.

The Project is expected to be implemented and offered as a service in most laboratories by the end of May 2012. ANZPAA NIFS can provide advisory assistance with any enquiries.
*Corresponding author: Linzi Wilson Wilde, Forensic Scientist, ANZPAA National Institute of Forensic Science, Melbourne, VIC, Australia, E-mail: linzi.wilson-wilde.nifs@anzpaa.org.au

Received May 07, 2012; Accepted May 07, 2012; Published May 09, 2012

Citation: Wilde LW (2012) Introduction of New DNA Marker Sets in Australian Forensic Laboratories. J Forensic Res 3:e109. doi:10.4172/2157-7145.1000e109

Copyright: (C) 2012 Wilde LW. This is an open-access article distributed under the terms of the Creative Commons Attribution License, which permits unrestricted use, distribution, and reproduction in any medium, provided the original author and source are credited. 